\title{
CASE-CONTROL STUDY OF MOSQUITO NETS AGAINST MALARIA IN THE AMAZON REGION OF COLOMBIA
}

\author{
NEAL ALEXANDER,* MAURICIO RODRÍGUEZ, LIGIA PÉREZ, JUAN CARLOS CAICEDO, JESÚS CRUZ, \\ GUILLERMO PRIETO, JOSÉ ANTONIO ARROYO, MARIA CRISTINA COTACIO, MARTHA SUÁREZ, \\ FERNANDO DE LA HOZ, AND ANDREW J. HALL \\ London School of Hygiene and Tropical Medicine, London, UK; Secretaría de Salud del Amazonas, Leticia, Amazonas, Colombia; \\ Universidad Nacional de Colombia, Leticia and Bogotá, Colombia
}

\begin{abstract}
The degree of effectiveness of mosquito nets against malaria in the Americas has remained uncertain. We carried out a case-control study of net use and mild malaria in the Amazonas state of Colombia. Two hundred ninety cases were enrolled via the Health Department services, and 977 community-based controls matched for age, sex, and place of residence. We found that a large proportion of the population (96\% of controls) slept under nets. Nevertheless, we found a benefit of impregnated nets compared with no net use: adjusted odds ratio (OR) for mild malaria $0.44,95 \%$ confidence interval (CI) $0.20-0.98$. Nonimpregnated nets had a benefit that was only slightly smaller but not statistically significant (OR for mild malaria $0.54,95 \%$ CI $0.25-1.18$ ). Travel in the previous month had an odds ratio of 6.2 (95\% CI 3.1-8.8) and a population attributable fraction of $13 \%$ compared with $11 \%$ for failure to use an impregnated net. We conclude that, in the Amazon region, promotion of mosquito net use and impregnation is justified, and that there is a need for measures to protect travelers from malaria.
\end{abstract}

\section{INTRODUCTION}

Malaria continues to be a major cause of morbidity and mortality in tropical and subtropical countries of the world, particularly in Africa. In Latin America, 1.1 million slideconfirmed cases were reported to the Pan American Health Organization (PAHO) in $1996,{ }^{1}$ representing a major public health problem for the affected countries. In Colombia in the 1990s, the annual number of cases ranged between 100,000 and 200,000, about double the number in the $1980 \mathrm{~s}^{2}$

Health sector reform has, in many countries, led to malaria control being changed from a vertical program to an integrated, local-level activity. In Colombia, malaria vector control has devolved from the Ministry of Social Protection to state (departamento) level and even, in a few cases, to district (municipio) level. At the same time, the main control activity is shifting from house spraying with residual insecticides to the impregnation of mosquito nets, with more emphasis on prompt diagnosis and treatment. ${ }^{3}$

Insecticide-treated bed nets have been demonstrated to protect against malaria in some parts of the world, in particular sub-Saharan Africa, ${ }^{4-7}$ even when the nets are damaged. ${ }^{8}$ These benefits have been demonstrated most clearly in children and pregnant women. Moreover, available evidence does not suggest that older children suffer a "rebound" effect due to delayed acquisition of immunity. ${ }^{9}$ However, it is not clear whether the results can be generalized to Latin America. As reviewed by Zimmerman and Voorham ${ }^{10}$ and Kroeger and others, ${ }^{11}$ available results from the Americas are equivocal and are thought to depend, at least in part, on the timing of vector biting. To assess the degree of protection from mosquito nets, as used in the areas over beds or hammocks, and hence to inform malaria control policy, we carried out a case-control study of incident malaria in urban and rural parts of the Colombian Amazon.

\footnotetext{
* Address correspondence to Neal Alexander, Infectious Disease Epidemiology Unit, Department of Infectious and Tropical Diseases, London School of Hygiene and Tropical Medicine, Keppel Street, London WC1E 7HT, United Kingdom. E-mail: neal.alexander@ lshtm.ac.uk
}

\section{MATERIALS AND METHODS}

Study area. The study was carried out from May 2001 to December 2003 in the Leticia, Puerto Nariño, and Tarapacá districts of Amazonas state (Departamento del Amazonas) in southeastern Colombia, near the borders with Brazil and Peru (Figure 1).

The study was done within the catchment areas of the health facilities of the eponymous settlements of each of the three districts. Leticia town lies on the Amazon river and, in 2003 , had a population estimated as $68 \%$ of the district total of 27,782 , the rest of the district being rural, according to projections from the 1993 national census (http://www.dane. gov.co/inf_est/censo_demografia.htm). Puerto Nariño is a rural district upstream from Leticia, whose projected 2003 population was 6,823 , of which $23 \%$ was estimated to be the main settlement. Tarapacá district is to the north of Leticia, on the river Putumayo. The district's projected 2003 populations was 3,979 , with $44 \%$ in the main settlement.

Malaria transmission occurs throughout the year in Tarapacá and is usually greatest between August and December. ${ }^{12}$ In the other two areas, transmission is lower and only occurs during or after the wet season, usually in the second half of the year. ${ }^{12}$ The ratio of malaria cases with Plasmodium vivax to those with Plasmodium falciparum is roughly 2:1; for example, in 1996-1997 it was 63\%:37\%. ${ }^{12}$ The most important Anopheles species in the Amazon region are Anopheles darlingi and Anopheles oswaldoi. ${ }^{12,13}$ A detailed description of the vectors in the current study area will be presented elsewhere. The catchment areas of the health services include both rural and urban areas. In the former, transport is largely by boat, so settlements far from a navigable river are hard to reach. Therefore, enrollment was restricted to the urban and peri-urban areas of Leticia and to specified areas of Puerto Nariño and Tarapacá (each main settlement, plus 15 and 7 villages, respectively, the largest of which are shown in Figure 1). The study was based in the state Health Department (Secretaría de Salud del Amazonas) in Leticia.

Malaria control program. The Health Department continued its normal malaria control measures throughout the study. Vector control includes impregnation of existing nets, 

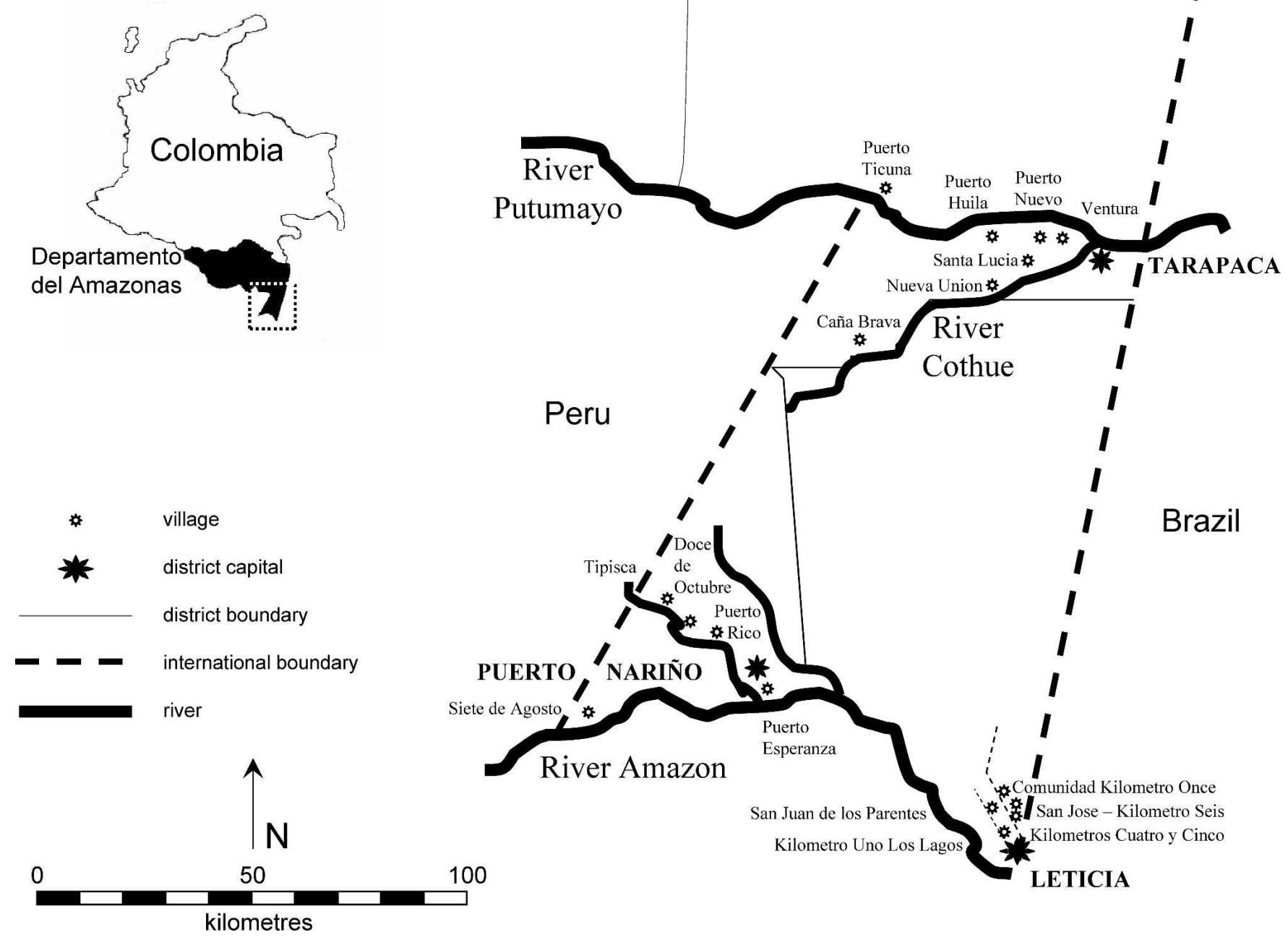

Figure 1. Map of study area. which have typically been bought from local shops, and are mostly rectangular and made of nylon, with a very few of cotton. A small proportion of nets have been donated from the departmental control program. Within the current study, no nets were distributed, other than to replace those taken for measurement of residual insecticide. Deltamethrin is used, either as $2.5 \%$ suspension concentrate or tablets (K-Othrine $25 \mathrm{SC}$ or K-O Tab, Aventis CropScience Colombia S.A., Bogotá, Columbia). For each method, the aim is to deposit 25 $\mathrm{mg} / \mathrm{m}^{2}$. In the 3 years 2001-2003, 2,431 nets were treated in the Tarapacá area, 1,817 in Leticia, and 2,007 in Puerto Nariño. Households are asked not to wash these nets for 6 months after impregnation.

Malaria cases are identified by both active and passive detection. Each village's primary health worker makes weekly house to house visits and takes a blood slide from those with malaria symptoms. In Leticia, there are no weekly visits but, when a case presents to the health service, outbreak control is done in their neighborhood. The slides are taken to the laboratory in each district's main settlement, where they are read by a trained laboratory technician. When the blood slide is positive for malaria, antimalarial drugs are administered as follows: chloroquine plus primaquine for $P$. vivax; chloro- quine (or amodiaquine when available) plus sulfadoxine/ pyrimethamine plus primaquine for $P$. falciparum. All positive slides, plus $10 \%$ of negative ones, are re-read by a second laboratory technician in the reference laboratory in Leticia. In Tarapacá and Puerto Nariño, the health department provides the only malaria diagnostic service. In Leticia, there are other facilities but all their positive slides are re-read by the health department.

Study design. The study had a matched case-control design. Cases were people diagnosed with malaria by the health services as described in the previous paragraph: most of the current authors are employees of the health department. Eligibility criteria for cases and controls are described in detail in Table 1. In summary, the study definition of a malaria episode required both a positive blood slide and specific symptoms. Therefore, if a potential control did not report those symptoms, they would be eligible as a control (subject to meeting the other criteria). If, on the other hand, they did report those symptoms, then the health department records were checked for a positive slide, in which circumstance they would not be eligible as a control. It is not possible to confidently separate new from recurrent infections (especially for $P$. vivax), but we used a cutoff of 28 days as an approximation. Similarly, 
TABLE 1

Eligibility criteria

\begin{tabular}{l}
\hline Applied only to cases \\
- A slide positive for trophozoites of any species of \\
Plasmodium but without a slide positive for the same species \\
in the previous 28 days. \\
- Symptoms characteristic of malaria in the previous 2 weeks, \\
specifically, fever with one of the following: chills, sweating, \\
headache, vomiting, or general malaise. \\
- None of the following signs and symptoms of severe or \\
complicated malaria: Axillary temperature $\geq 40.5^{\circ} \mathrm{C} ; P$. \\
falciparum parasitemia more than 50,000 asexual forms per \\
microliter; convulsions in the previous 24 hours; persistent \\
vomiting; unable to sit, stand, or drink; delirium, lethargy, or \\
unconsciousness; pronounced pallor with tachycardia and \\
heart murmur; difficulty breathing, with a respiratory rate \\
> $24 /$ min in adults or $>40 /$ min in children $<2$ years; systolic \\
blood pressure of $<70$ mm of Hg in adults or $<50$ mm of $\mathrm{Hg}$ \\
in children; jaundice; amber-colored urine; spontaneous \\
bleeding or mucosa or digestive tract. \\
- Not pregnant. \\
Applied to both cases and controls \\
- Age at least 1 year. \\
- Main residence in the study area for at least 1 month. \\
Apot police or military personnel. \\
Aplied only to controls \\
- If had symptoms characteristic of malaria (see above) in the \\
previous 2 weeks, were excluded if health records showed a \\
positive blood slide in that time.
\end{tabular}

people who had moved into the study area, as new residents, in the previous month were excluded. However, we did not attempt to exclude episodes contracted by established residents when traveling outside the study area: in fact, these were of interest to the study. Police and military personnel were excluded because their inclusion requires special permission from the ministry of defense.

Controls were matched on age, sex, and area of residence. The age bands were 1-5, 6-10, 11-20, 21-30, 31-40, 41-50, and $\geq 51$ years. In rural districts, and in Puerto Nariño, the matching area of residence was the whole settlement. The main settlement of Tarapacá was split into two parts: subject or not to inundation by the river Putumayo. In Leticia, matching was done on barrio, or town district. For the identification of potential controls, existing census lists, maintained by the health department, were used. If there were more than four, a table of random numbers was used. Concurrent sampling was used; in other words, each control was selected from those at risk when a new case is diagnosed. This means that, for our malaria end point, it was possible for a control to be enrolled as a case later, and vice versa. ${ }^{14}$

The sample size was calculated following Hayes and others, ${ }^{15}$ aiming to detect an odds ratio of 0.67 for net use, approximately the magnitude found in The Gambia. ${ }^{16}$ We also assumed: that two thirds of the controls would use nets (based on unpublished data from state health department), $90 \%$ power, significance level of $5 \%$ (two-sided), and with a $25 \%$ increase to allow for control of confounding variables. The target number of controls per case was four, although three was used in the sample size calculation to allow for the fact that the matching criteria restrict the number eligible. The above parameters gave a sample size of 453 cases. Based on past records of the health department, we planned to enroll this number in two seasons of peak malaria transmission.

Potential risk factors. The same questionnaire, in Spanish, was used for both cases and controls. Information was collected on whether the person slept the previous night on a bed, hammock or floor, and whether they did so under a mosquito net (toldillo); other methods for protection against mosquitoes; washing and impregnation of any net, and whether it was bought or donated; travel history during the past month, including destinations and net use when traveling; self-identified ethnic group; education; occupation; and house construction, including the presence or absence of eaves. In addition, for the roof, floor, and walls, the principal construction was recorded, and the presence or absence of holes and cracks. Condition of the net was assessed by measuring the total circumference of all holes and tears in the net.

Measurement of residual insecticide. Bioassay was used to measure the persistence of insecticide and relate it to respondents' recall of frequency of washing and insecticide treatment. Following Curtis and others, ${ }^{17}$ part of the net, usually the middle of one side, was wrapped around a cubical wire frame of side $15 \mathrm{~cm}$. One experiment was done on each of 67 nets, using mosquitoes that had been obtained from human bait catches (to be described elsewhere). The average number of mosquitoes per experiment was 11.5 (range 6-20). Time to each knockdown was registered, up to a maximum of 15 minutes. Bioassays were conducted using any of 5 species of blood-fed Anopheles collected in the study area (An. darlingi, An. oswaldoi, An. nuñeztovari, An. mediopunctatus, and An. braziliensis).

Wealth ranking. To measure socioeconomic status, a possible confounder of an association between net use and malaria, we used the method of Grandin. ${ }^{18}$ This was done within each matching area. Because each case is compared only to their matched controls, we do not need, and do not attempt, to measure differences between matching areas. Local informants were asked to rank households according to their perception of socioeconomic status. We began by choosing the local informants; they were long-standing members of the community, such as community leaders, healers, and primary health workers. A household was defined as group of persons living under the same ceiling and eating from the same pot. Households were ranked within the same geographical areas used for matching cases and controls. The names of the household heads were written on cards and shuffled. The informants made piles of them, according to the indigenous concept of wealth of each household. The informants chose the number of categories, subject to it being at least 3: in practice it varied from 3 to 10 . Finally, the informants were asked to comment on the factors that were important in defining their categories.

Data processing and analysis. The data were entered using Epi Info version 6 (Centers for Disease Control, Atlanta, GA). Double entry was done for the main risk factor form, but the wealth ranking and entomological knockdown data were single-entered. Statistical analysis was done with Stata version 8 (StataCorp, College Station, TX).

The analysis of the wealth ranking was complicated by the fact that different informants may use different numbers of categories. This means that, for example, a difference of three ranks between a case and control may, in one exercise, cover the entire wealth range, but in another only one third of it. In addition, individual cases and controls may have multiple ratings over the course of the study, based on different numbers of ranks. To allow for this, the ranks were related to a hypo- 
thetical underlying continuous scale, arbitrarily taken to run from 0 to 10, with higher numbers indicating more wealth. Each informant was assumed to be dividing this scale into a number of equal bands, and a household's rank was converted to a score equal to the midpoint of the corresponding band. For example, rank 3 in a four-category system was taken to be the midpoint of the third of four equal bands, that is, midway between 5 and 7.5 (i.e., a score of 6.25). These scores were then averaged over informants, for each ranking exercise. For analysis, each case's score was taken from the exercise that was nearest to the date of their risk factor questionnaire, with control data taken from that same exercise, thereby maintaining the matched nature of the analysis.

Risk factors were assessed by conditional logistic regression. The concurrent sampling design means that the odds ratio estimates the disease rate ratio $(\mathrm{RR}) .{ }^{14,19}$ To simultaneously compare the use of impregnated net, unimpregnated net, or no net, we use a triangle plot, also known as a profile plot. $^{20,21}$ The three odds ratios can be shown in this twodimensional graph because of their mutual dependency. ${ }^{21} \mathrm{~A}$ multivariable conditional logistic regression model, for factors in addition to net use, was built by adding other factors one at at time, and retaining those which were statistically significant (by likelihood ratio test) or materially confounded the effect of net use (changed the odds ratio estimate by more than $15 \%$ ). The population attributable fraction (PAF) of selected risk factors-i.e., the proportion of all cases which would be prevented by removing that risk factor, assuming it is causal, and its effect measured accurately-were estimated by multiplying the proportion of exposed cases by (RR $1) / R R$, where $R R$ is the adjusted measure. For multilevel exposures, the total PAF is the sum of the single-level PAFs. ${ }^{22}$ For the bioassay, mosquito knockdown times were analyzed by the Cox regression technique of survival analysis, using the sandwich estimator ${ }^{23}$ ("robust cluster" in Stata) to allow for clustering within nets. This yields ratios of the rates at which mosquitoes are knocked down.

Ethical approval. Approval was given by the ethics committees of Instituto Nacional de Salud and the London School of Hygiene and Tropical Medicine. Potential cases and controls read, or had read to them, an information sheet outlining the rationale and procedures of the study. They were then asked to record their consent on a form, by signature or finger print. Consent of a parent or guardian was required for those less than 18 years.

\section{RESULTS}

The enrolment of cases over time is shown in Figure 2, and Table 2 shows a basic description of the study participants, comprising 290 cases and 977 controls. The vast majority $(89 \%)$ of cases were enrolled in the Tarapacá area, and the number of $P$. vivax cases was almost double that of $P$. falciparum. The average number of controls per case was 3.4 , compared with the target of 4 . The average time from taking of the case's blood slide to the study interview was 5.0 days for cases and 5.1 days for controls. The vast majority (94\%) of nets had been purchased, and among controls (who are more representative of the general population), most slept either on a bed $(44 \%)$ or the floor $(51 \%)$ rather than a hammock $(0.7 \%)$. The mean number of occupants of controls' nets was 2.5 .

Table 3 shows single variable analysis for the sleeping un-

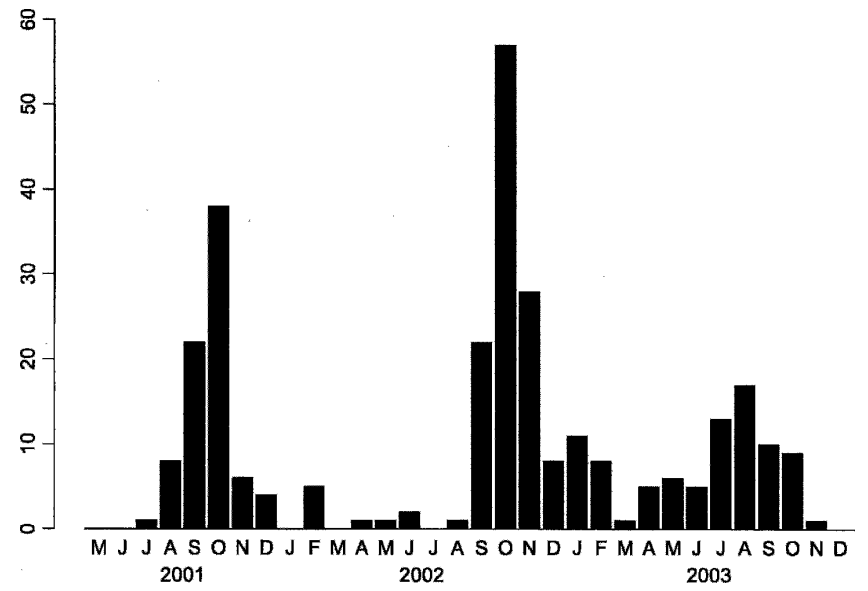

FIGURE 2. Malaria cases by month, enrolled via passive and active surveillance by the public health system (see the "Materials and Methods" section for more details).

der a net, and the other main candidate risk factors. More than $90 \%$ of both cases and controls reported sleeping under a net the previous night. However, cases comprised a disproportionate number of the non-users: the odds ratio (OR) for malaria for those using an ever-impregnated net, relative to no net use, was 0.42 , which was statistically significant at the $5 \%$ level (95\% confidence interval [CI] 0.20-0.87, $P=0.021$ ). The three-way comparison of net use is shown in Figure 3. The ellipsoidal confidence region is narrower for the comparison of impregnated and unimpregnated nets (lower axis), reflecting the fact that most people did use a net of either type. Other positive risk factors (i.e., associated with increased risk of malaria), when considered individually, were ethnic group, with Ticunas having a lower risk than others; sleeping elsewhere in the previous month; using a non-net method against mosquitoes (most commonly bomba or insecticide spray), and having a shorter period of normal residence

TABLE 2

Demographic and parasitological characteristics of study participants

\begin{tabular}{lcc}
\hline & $\begin{array}{c}\text { Number of } \\
\text { cases }(\%)\end{array}$ & $\begin{array}{c}\text { Number of } \\
\text { controls }(\%)\end{array}$ \\
\hline Sex* & $156(54)$ & \\
Male & $134(46)$ & $521(53)$ \\
Female & & $456(47)$ \\
Age (years)* & $59(20)$ & $212(22)$ \\
$1-5$ & $61(21)$ & $210(21)$ \\
$6-10$ & $63(22)$ & $223(23)$ \\
$11-20$ & $49(17)$ & $155(16)$ \\
$21-30$ & $26(9)$ & $83(9)$ \\
$31-40$ & $13(4)$ & $41(4)$ \\
$41-50$ & $19(7)$ & $53(5)$ \\
$\geq 51$ & $258(89)$ & $875(90)$ \\
Area* & $9(3)$ & $31(3)$ \\
Tarapacá & $23(8)$ & $71(7)$ \\
Puerto Nariño & $178(61)$ & - \\
Leticia & $92(32)$ & - \\
Plasmodium species & $20(7)$ & 977 \\
$P$. vivax & 290 & - \\
$P$. falciparum & Mixed & \\
Total & Matching factors. The percentages for cases and controls are not exactly equal, because
\end{tabular}

the target of four controls per case was not always met. 
TABLE 3

Risk factors for malaria*

\begin{tabular}{|c|c|c|c|c|c|c|}
\hline Potential risk factors & $\begin{array}{l}\text { Number of } \\
\text { cases (\%) }\end{array}$ & $\begin{array}{c}\text { Number of } \\
\text { controls (\%) }\end{array}$ & $\begin{array}{l}\text { Crude odds } \\
\text { ratio }(95 \% \mathrm{CI})\end{array}$ & $P$ & $\begin{array}{l}\text { Adjusted odds } \\
\text { ratio (95\% CI) }\end{array}$ & $P$ \\
\hline \multicolumn{7}{|c|}{ Used net previous night ( 5 missing) } \\
\hline No & $20(7)$ & $39(4)$ & 1 & & 1 & \\
\hline Yes, but never impregnated & $103(36)$ & $344(35)$ & $0.53(0.26-1.07)$ & 0.075 & $0.54(0.25-1.18)$ & 0.12 \\
\hline Yes, impregnated $\dagger$ & $167(58)$ & $589(61)$ & $0.42(0.20-0.87)$ & 0.021 & $0.44(0.20-0.98)$ & 0.043 \\
\hline \multicolumn{7}{|l|}{ Other anti-mosquito measures } \\
\hline No & $253(87)$ & $897(92)$ & 1 & & 1 & \\
\hline Yes & 37 (13) & $80(8)$ & $1.96(1.18-3.24)$ & 0.009 & $2.02(1.16-3.49)$ & 0.012 \\
\hline \multicolumn{7}{|l|}{ Ethnic group } \\
\hline Ticuna & $193(67)$ & $713(73)$ & 1 & & 1 & \\
\hline Huitoto & $28(10)$ & $54(6)$ & $2.73(1.50-4.99)$ & 0.001 & $2.77(1.49-5.18)$ & 0.001 \\
\hline Other indigenous & $30(10)$ & $80(8)$ & $1.94(1.10-3.45)$ & 0.023 & $1.83(1.02-3.29)$ & 0.043 \\
\hline Other & $39(13)$ & $130(13)$ & $1.52(0.87-2.63)$ & 0.14 & $1.31(0.73-2.34)$ & 0.37 \\
\hline \multicolumn{7}{|l|}{ Main occupation (8 missing) } \\
\hline$\leq 5$ years, or student & $152(53)$ & $527(54)$ & 1 & & & \\
\hline Housewife & $34(12)$ & $103(11)$ & $1.10(0.61-1.97)$ & 0.76 & & \\
\hline Farmer or fisher & $73(25)$ & $274(28)$ & $0.60(0.33-1.11)$ & 0.10 & & \\
\hline Other & $29(10)$ & $67(7)$ & $1.33(0.65-2.70)$ & 0.43 & & \\
\hline \multicolumn{7}{|l|}{ Education (7 missing) } \\
\hline No formal & $77(27)$ & $285(29)$ & 1 & & & \\
\hline Primary school & $164(57)$ & $560(58)$ & $1.29(0.79-2.10)$ & 0.32 & & \\
\hline Secondary school or higher & 48 (17) & $126(13)$ & $2.03(1.03-4.00)$ & 0.04 & & \\
\hline \multicolumn{7}{|c|}{ Slept elsewhere in past month ( 3 missing) } \\
\hline No & $243(84)$ & $931(96)$ & 1 & & 1 & \\
\hline Yes & 47 (16) & $43(4)$ & $5.27(3.14-8.84)$ & $<0.001$ & $5.23(3.10-8.84)$ & $<0.001$ \\
\hline \multicolumn{7}{|c|}{ Time lived in study area (28 missing) } \\
\hline 1 month to $\leq 5$ years & $111(40)$ & $341(36)$ & 1 & & & \\
\hline$>5$ years to $\leq 12$ years & $85(30)$ & $299(31)$ & $0.67(0.42-1.05)$ & 0.082 & & \\
\hline$>12$ years & $84(30)$ & $319(33)$ & $0.52(0.32-0.84)$ & 0.007 & & \\
\hline \multicolumn{7}{|c|}{ Wealth score (0-10 scale, 432 missing) } \\
\hline $0-3.33$ & $35(25)$ & $147(24)$ & 1 & & & \\
\hline $3.34-6.66$ & $134(61)$ & $358(58)$ & $1.04(0.67-1.59)$ & 0.87 & & \\
\hline $6.67-10$ & $31(14)$ & $110(18)$ & $0.71(0.41-1.25)$ & 0.24 & & \\
\hline \multicolumn{7}{|c|}{ Holes or cracks in wall ( 25 missing) } \\
\hline No & $31(11)$ & $127(13)$ & 1 & & & \\
\hline Yes & $253(89)$ & $831(87)$ & $1.32(0.82-2.13)$ & 0.25 & & \\
\hline
\end{tabular}

in the study area (but always at least 1 month, as this was an eligibility criterion). Education of secondary or higher level was also associated with higher risk but with borderline significance $(P=0.04)$. A total of 29 wealth-ranking exercises were done, 28 in the Tarapacá area and the other in the Puerto Nariño area; the process was not practical for urban Leticia. Six of the exercises used 3 informants, and the remaining 23 used 1 . The average number of households ranked per exercise was 38, and the numbers of cases and controls assessed are shown in Table 3. There was no apparent association between malaria and higher wealth ranking, whether split into three levels or considered as a continuous variable.

When building up the multivariable model, ethnic group, sleeping elsewhere, and use of other anti-mosquito measures retained their statistical significance. The final model is shown in Table 3. Education, condition of the house walls, duration of living in the study area, and occupation did not materially confound the association with impregnated net use: the adjusted ORs were, respectively, 0.47, 0.47, 0.47, and 0.44, compared with 0.44 in the final model. Wealth ranking was not included because of the large number of missing values, and the lack of evidence for association with the outcome. In the final model, use of impregnated net, relative to no net use, is still associated with a protective effect, in terms of mild malaria, of slightly over $50 \%$, but now has only borderline sta-

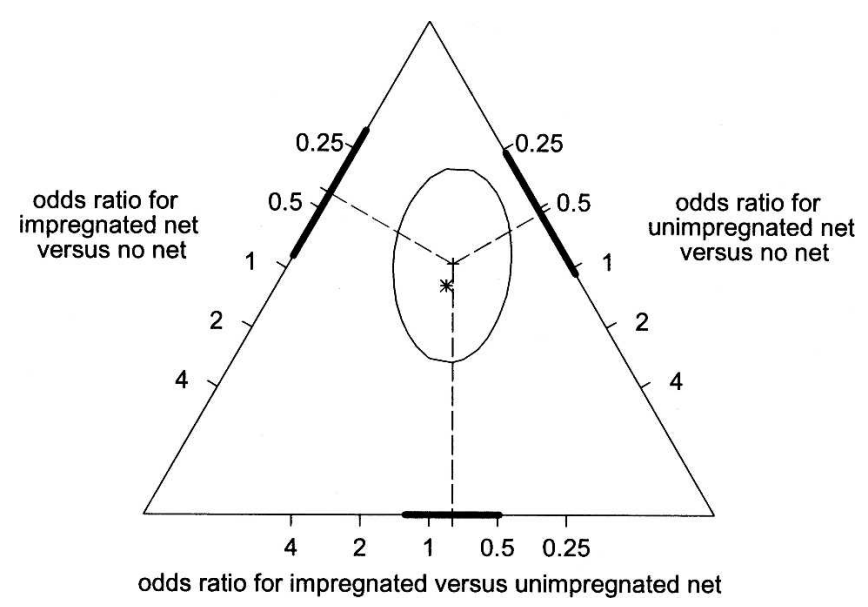

FIGURE 3. Triangle plot of the odds ratios for sleeping under impregnated net, unimpregnated net, or no net, as risk factors for malaria. Each axis shows one of the mutually dependent odds ratios (from Table 3), with the + symbol indicating their joint effects and the univariate confidence interval in bold. Each odds ratio is the ratio of the other two, so a point defined by any of the two axes can be read off on the third. The ellipsoid is the joint $95 \%$ confidence region, centered on the point estimate. The $*$ symbol indicates the summary odds ratios from Lengeler's systematic review. 
tistical significance $(\mathrm{OR}=0.44,95 \%$ CI $0.20-0.98, P=$ 0.043). Although never-impregnated nets had a weaker effect, which was not statistically significant, it was close to that for impregnated nets, and the two confidence intervals largely overlap.

When the travelers were split according to net use when traveling, those who did not use a net had an even higher odds ratio (17.7, Table 4). Among nets owned by controls, $43 \%$ had no holes or tears, and, in another $31 \%$, they were of total circumference $20 \mathrm{~cm}$ or less. Table 4 shows that neither condition of the net, nor washing frequency, showed any sign of affecting the risk of malaria. Surprisingly, the protective effect was greater for $P$. vivax than $P$. falciparum, although the latter's confidence intervals are wide, with baseline net group having only four cases.

To investigate the accuracy of the reported treatment status of the nets, we bioassayed 67 nets with 770 Anopheles mosquitoes. 18 nets were from cases, 24 from controls, and 25 from people who had been neither. Control nets tended to have a higher death rate, but not statistically significantly so (rate ratio $1.30,95 \% \mathrm{CI} 0.81-2.10, P=0.28)$. We categorized the nets into those reported never impregnated $(N=8)$, those reported impregnated 6 months or more ago $(N=34)$, and those reported impregnated less than 6 months ago $(N=$ $25)$. Within these groups, the proportions of mosquitoes surviving till 15 minutes were, respectively, 63 of 74 (85\%), 207 of $409(51 \%)$ and 101 of 287 (35\%). It was not always possible to calculate the exact median knockdown time per net, because in 34 experiments ( 8 of 8,19 of 34 , and 7 of 25 , respectively, by impregnation category) the majority of mosquitoes were not knocked down before the limit of observation of 900 seconds. However, the medians of the net-wise median knockdown time were $>900,>900$, and 740 seconds, respectively. The knockdown rate ratios for the two impregnated net groups, relative to non-impregnated, were 4.39 (95\% CI 1.94-9.9) and 6.26 (2.73-14.4), respectively, $P<0.001$ for each. Therefore, the reported impregnation status was strongly associated with anti-mosquito activity. Differences in knockdown rate between the Anopheles species were not statistically significant $\left(\chi_{4}^{2}=3.16, P=0.53\right)$. Nets were also categorized into not impregnated; impregnated, and washed in the previous 14 days; and impregnated but not washed in the previous 14 days. There was negligible difference between the last two levels $($ knockdown rate ratio $=1.04, P=0.92)$.

\section{DISCUSSION}

There have been few evaluations of treated or untreated mosquito nets in the Americas. Zimmerman and Voorham concluded that most studies suffered from design flaws, and that it would be "premature to use insecticide-impregnated mosquito nets or other materials as a major component of an integrated malaria control program in the Americas as this time." ${ }^{10}$ Early vector biting and heterogeneous human activity patterns may tend to limit the benefit of nets, while relatively low incidence, and a high proportion of $P$. vivax malaria, make it difficult to measure the extent of any such benefit. The only American studies included in Lengeler's systematic review ${ }^{7}$ were those done by Kroeger and others in

TABLE 4

Detailed breakdown of mosquito net effects*

\begin{tabular}{|c|c|c|c|c|}
\hline Potential risk factors & $\begin{array}{l}\text { Number of } \\
\text { cases (\%) }\end{array}$ & $\begin{array}{c}\text { Number of } \\
\text { controls (\%) }\end{array}$ & $\begin{array}{c}\text { Crude odds } \\
\text { ratio }(95 \% \mathrm{CI})\end{array}$ & $P$ \\
\hline \multicolumn{5}{|l|}{ Net use and time since impregnation ( 25 missing) } \\
\hline No net & $20(7)$ & $39(4)$ & 1 & \\
\hline Net, never impregnated & $103(36)$ & $344(36)$ & $0.54(0.26-1.09)$ & 0.083 \\
\hline Impregnated $\geq 6$ months ago & $61(21)$ & $196(21)$ & $0.48(0.21-1.13)$ & 0.094 \\
\hline Impregnated $<6$ months ago & $103(36)$ & $376(39)$ & $0.40(0.18-0.87)$ & 0.020 \\
\hline \multicolumn{5}{|l|}{ Net use and washing frequency (47 missing) } \\
\hline No net & $20(7)$ & $39(4)$ & 1 & \\
\hline Net, never impregnated & $103(37)$ & $344(37)$ & $0.61(0.30-1.24)$ & 0.17 \\
\hline Impregnated and washed in previous 2 weeks & $67(24)$ & $234(25)$ & $0.43(0.19-0.96)$ & 0.041 \\
\hline Impregnated and not washed in previous two weeks & $90(32)$ & $323(34)$ & $0.45(0.21-1.00)$ & 0.050 \\
\hline \multicolumn{5}{|c|}{ Net condition (total circumference of holes and tears; 3 missing) } \\
\hline No net & $20(7)$ & $39(4)$ & 1 & \\
\hline Net with gaps $\geq 21 \mathrm{~cm}$ & $62(21)$ & $213(22)$ & $0.51(0.24-1.07)$ & 0.076 \\
\hline Net with gaps $\leq 20 \mathrm{~cm}$ & $89(31)$ & $303(31)$ & $0.49(0.24-1.00)$ & 0.049 \\
\hline Net with no gaps & $119(41)$ & $419(43)$ & $0.47(0.24-0.95)$ & 0.034 \\
\hline \multicolumn{5}{|l|}{ Net use and travel in previous month ( 8 missing) } \\
\hline Did not travel & $243(85)$ & $931(96)$ & 1 & \\
\hline Travelled, used net on trip & $33(12)$ & $37(4)$ & $4.10(2.31-7.28)$ & $<0.001$ \\
\hline Travelled, did not use net & $11(4)$ & $4(0.4)$ & $17.7(3.88-80.8)$ & $<0.001$ \\
\hline \multicolumn{5}{|l|}{ P. vivax malaria $\dagger$} \\
\hline \multicolumn{5}{|l|}{ Whether used net previous night ( 5 missing) } \\
\hline No & $18(9)$ & $33(5)$ & 1 & \\
\hline Yes, but never impregnated & $84(42)$ & $288(43)$ & $0.47(0.22-1.01)$ & 0.052 \\
\hline Yes, impregnated & $96(48)$ & $351(52)$ & $0.34(0.15-0.78)$ & 0.011 \\
\hline \multicolumn{5}{|l|}{ P. falciparum malaria $\dagger$} \\
\hline \multicolumn{5}{|l|}{ Whether used net previous night } \\
\hline No & $4(4)$ & $7(2)$ & 1 & \\
\hline Yes, but never impregnated & $28(25)$ & 89 (24) & $0.52(0.10-2.59)$ & 0.42 \\
\hline Yes, impregnated & $80(71)$ & $272(74)$ & $0.50(0.10-2.61)$ & 0.50 \\
\hline
\end{tabular}


Ecuador, Colombia and Peru, ${ }^{24}$ of which only the Colombian one showed a benefit of net use, which was in terms of clinical malaria episodes.

The current study was intended to add to the available evidence, and, more specifically, to address the need of the health services of the tri-national border area for guidance on the role of nets in their health programs. ${ }^{25}$ Despite running the study for three peak transmission seasons instead of the planned two, we were able to enrol only 290 cases rather than the target of 453. Even had resources permitted us to run the study for another year, we would not have been confident of reaching the target number. Nevertheless, it is a large study when compared with others done in the Amazon region, and has yielded useful findings. The proportion of people using nets in the area was much greater than expected $(96 \%$ of controls), so there does not seem to be a need for mass distribution of nets. Impregnated nets were associated with a reduction in malaria of more than $50 \%$, relative to no net use. The protective efficacy from the multivariable model was $56 \%$, similar to the corresponding summary value of $48 \%$ from Lengeler's Table $5 .^{7}$ In our study, the advantage of impregnated over non-impregnated nets was not statistically significant (protective efficacy of $21 \%$, again similar to Lengeler's summary value of $16 \%$, as shown in Figure 3), nor was the advantage of more- over less-recently treated nets. On the other hand, a recent randomized trial, in the Amazonas State of Venezuela, of lambdacyhalothrin- versus placebo-treated nets found a protective efficacy of $55 \% .^{26}$ The modest effect in our study, despite the increased knockdown rate for impregnated nets (rate ratio of 6.2 or 4.6 , compared with nets reported ever impregnated, depending on how recently the impregnation was done), suggests that a large proportion of mosquito biting may occur when people are not sleeping under their nets. This was explored in parallel entomological studies, which will be reported separately. We found little evidence of increased risk associated with either greater washing frequency, or of larger gaps in nets. Overall, these findings suggest that, although impregnated nets are effective against malaria, the possible commitment of greater resources to impregnation should be weighed against other candidate measures, such as reinforcement of early diagnosis and treatment. However, variation in terms of vector species, ${ }^{27}$ and possibly of human behavior, mean that optimal policies may vary within the Amazon region.

Travel has often been found to be a risk factor for malaria, including recently in the Pacific coast region of Colombia. ${ }^{28}$ In our study, travel in the previous month was a strong risk factor, with a population attributable fraction greater than that of non-use of impregnated nets $(13 \%$ and $11 \%$ respectively, the latter being the total of $7 \%$ for using an untreated net, plus $4 \%$ for using no net at all). Travel increased the risk of malaria by a factor of more than 5; by more than 17 in those who did not use a net while away. This suggests that promotion of preventive measures in travellers could be an effective measure. On the other hand, there are signs that there is already good awareness of the risks: $90 \%$ of controls used a net when traveling, and $72 \%$ of traveling cases believed they knew where they had contracted malaria. In this part of Colombia, international travel complicates the picture, with most cases treated in Leticia being residents of Brazil (and hence not eligible for the current study).

The excess malaria risk associated with non-net anti- mosquito measures - mostly sprays - is perhaps surprising, although has been found elsewhere. ${ }^{29}$ This association may result from higher use of sprays in areas with higher background rates of mosquito biting. On the other hand, in our study, they were associated with a lack of net use in controls: $41 \%$ of non-net users used them, but only $5 \%$ of impregnated net users. Therefore, another explanation for the excess risk among users of spray is that they do not feel the need to use nets, and educational measures against any such tendency could be worthwhile.

Surprisingly, unlike other studies in the Amazon region, ${ }^{30}$ we found no association between malaria and socioeconomic variables such as occupation, locally perceived wealth ranking, and level of education. The excess risk associated with higher levels of education, as found in the univariable analysis, did not persist in the multivariable analysis, possibly because of confounding with travel. These negative findings may partly be due to problems we experienced with the wealth ranking technique. In particular, the local informants sometimes omitted people who were temporarily absent; it was difficult to prevent them conferring with each other; and the process was not feasible in Leticia. Matching on village probably reduced the power to detect some differences, such as those resulting from the lower fecundity of Cothue river compared with the Putumayo. However, there is still withinvillage variability: each village in the Tarapacá district has at least one household with a regular cash income, while the majority do not. Moreover, unlike Guthmann and others in Peru, ${ }^{31}$ we did not find house quality to be associated with malaria risk. In additional analysis, we used principal components to try to distil the information on education, occupation, and housing condition (construction material, and the presence of ceiling, eaves, and nonclosable gaps). However, neither of the first two principal components showed any association with malaria risk ( $P>0.1$ for each). These results may be due, at least in part, due to suboptimal measurement methods: for example we recorded only the presence or absence of gaps in the construction, not their size. This, in turn, may have caused some degree of residual confounding in our estimates of the effects of mosquito nets.

Our case-control design does not allow for spatial variation in unobserved confounding variables occurring on a scale smaller than the geographical areas used for matching. In the Tarapacá district, from which $89 \%$ of the cases were enrolled, the villages ranged in size (based on tape measurements) from $180 \times 60 \mathrm{~m}$ (Puerto Ticuna) to $410 \times 170 \mathrm{~m}$ (Ventura), with the houses arranged in approximately rectangular nuclear patterns. Only in Puerto Huila were there any (two) houses outside the central area. Only two cases and three controls were enrolled from these, and, unsurprisingly, omitting them from the analysis did not change the results appreciably. The eponymous main settlement of Tarapacá was split, for the purpose of matching, into two areas, according to inundation risk. These two areas are not regularly shaped, but (based on GPS readings) their largest internal distances are approximately $1050 \mathrm{~m}$ and $600 \mathrm{~m}$, respectively. These matching areas are not overly large, in terms of the requirement for a minimum the number of inhabitants to furnish age-matched controls. However, their geographical sizes are appreciable in comparison, for example, to the 500-m distance over which risk of malaria episodes was found to vary by a factor of 6 in Mozambique. ${ }^{32}$ If such spatial variation exists in our study 
area, it could be another source of confounding, and would not be allowed for in our analysis.

Although they do not have immediate implications for control, the differences between ethnic groups-specifically, the lower risk of Ticunas-merit further investigation. The Ticunas have a longer history of living in the study area, compared with groups such as the Boras and Huitotos who have arrived from the higher up the Putumayo-where malaria is less endemic - in the past 100 years. ${ }^{33}$ The difference in malaria risk cannot be solely ascribed to individual-level acquired immunity-although this may contribute ${ }^{34}$ _because the difference persisted after adjusting for time lived in the study area. Because controls were matched to cases within villages, the effects cannot be due to confounding by village. This suggests the possibility that the Ticunas have a raised frequency of a protective red cell or other mutation, which is conceivable, given the wide range of the Duffy $F Y^{*} A$ allele frequency $(54-95 \%)$ in indigenous South American populations. ${ }^{35}$

We have found insecticide-impregnated mosquito nets to protect against malaria in the Amazon region of South America, with the effect of nonimpregnated nets being similar in magnitude but not statistically significant. Although fine-scale spatial variation may have contributed to residual confounding, our findings favor the promotion of nets in similar areas, if they are not already widely used. In this part of Colombia, the vast majority of people do already sleep under nets, suggesting that other measures will need to be considered if the kernel of uncontrolled malaria is to be reduced, and there is a particular need for measures to protect travelers.

Received July 12, 2004. Accepted for publication January 24, 2005.

Acknowledgments: We are grateful to all residents of Tarapacá and the other two districts for their help and cooperation with the study; to Professor Chris Curtis for advice on the bioassays; and to Professor Jo Lines for advice on the running of the study and for comments on the manuscript.

Financial support: This work was supported by the United Kingdom Department for International Development, research project R7829, and the United Kingdom Medical Research Council grant number G7508177 to the Tropical Epidemiology Group.

Authors' addresses: Neal Alexander and Andrew J. Hall, Infectious Disease Epidemiology Unit, Department of Infectious and Tropical Diseases, London School of Hygiene and Tropical Medicine, Keppel Street, London WC1E 7HT, UK. Mauricio Rodríguez, Ligia Pérez, Juan Carlos Caicedo, Jesús Cruz, Guillermo Prieto, José Antonio Arroyo, and Maria Cristina Cotacio, Secretaría de Salud del Amazonas, Carrera 11 \#3-29, Leticia, Amazonas, Colombia. Martha Suárez, Universidad Nacional de Colombia, Vía Tarapacá Km 2 Leticia, Amazonas, Colombia. Fernando de la Hoz, Universidad Nacional de Colombia, Departamento de Salud Publica, Ciudad Universitaria, Cra 30, Calle 45 Bogotá, Colombia.

Reprint requests: Neal Alexander, Infectious Disease Epidemiology Unit, Department of Infectious and Tropical Diseases, London School of Hygiene and Tropical Medicine, Keppel Street, London WC1E 7HT, UK. Telephone: (+44) 207927 2483, Fax: (+44) 207636 8739, E-mail: neal.alexander@lshtm.ac.uk.

\section{REFERENCES}

1. Pan American Health Organization, 1998. Status of Malaria Programs in the Americas: XLV Report. Available at http:// 165.158.1.110/english/hcp/hct-mala.htm.

2. Ministerio de Protección Social, 2003. Malaria: Estrategias para Afrontar una Prioridad en Salud Pública. Universidad del
Valle, Cali: Ministerio de Protección Social, República de Colombia.

3. Kroeger A, Ordonez-Gonzalez J, Avina AI, 2002. Malaria control reinvented: health sector reform and strategy development in Colombia. Trop Med Int Health 7: 450-458.

4. Alonso PL, Lindsay SW, Armstrong JR, Conteh M, Hill AG, David PH, Fegan G, de Francisco A, Hall AJ, Shenton FC, Cham K, Greenwood BM, 1991. The effect of insecticidetreated bed nets on mortality of Gambian children. Lancet 337: 1499-1502.

5. Kamol-Ratanakul P, Prasittisuk C, 1992. The effectiveness of permethrin-impregnated bed nets against malaria for migrant workers in eastern Thailand. Am J Trop Med Hyg 47: 305-309.

6. Choi HW, Breman JG, Teutsch SM, Liu S, Hightower AW, Sexton JD, 1995. The effectiveness of insecticide-impregnated bed nets in reducing cases of malaria infection: a meta-analysis of published results. Am J Trop Med Hyg 52: 377-382.

7. Lengeler C, 2004. Insecticide-treated bednets and curtains for preventing malaria (Cochrane Review). The Cochrane Library, Issue 1. Chichester: John Wiley \& Sons, Ltd.

8. Carnevale P, Bitsindou P, Diomande L, Robert V, 1992. Insecticide impregnation can restore the efficiency of torn bed nets and reduce man-vector contact in malaria endemic areas. Trans R Soc Trop Med Hyg 86: 362-364.

9. Diallo DA, Cousens SN, Cuzin-Ouattara N, Nebie I, IlboudoSanogo E, Esposito F, 2004. Child mortality in a West African population protected with insecticide-treated curtains for a period of up to 6 years. Bull WHO 82: 85-91.

10. Zimmerman RH, Voorham J, 1997. Use of insecticideimpregnated mosquito nets and other impregnated materials for malaria control in the Americas. Pan American Journal of Public Health 2: 18-25.

11. Kroeger A, Gonzalez M, Ordonez-Gonzalez J, 1999. Insecticidetreated materials for malaria control in Latin America: to use or not to use? Trans R Soc Trop Med Hyg 93: 565-570.

12. Pérez L, Suárez M, Murcia L, de la Hoz F, Olano VA, Brochero H, Toro P, 1999. La malaria en el Amazonas: conocimientos, prácticas, prevalencia de parasitemia y evaluación entomológica en mayo de 1997. Biomédica 19: 93-102.

13. Branquinho MS, Lagos CB, Rocha RM, Natal D, Barata JM, Cochrane AH, Nardin E, Nussenzweig RS, Kloetzel JK, 1993. Anophelines in the state of Acre, Brazil, infected with Plasmodium falciparum, $P$. vivax, the variant $P$. vivax VK247 and P. malariae. Trans $R$ Soc Trop Med Hyg 87: 391-394.

14. Rothman KJ, Greenland S, 1998. Modern Epidemiology. Philadelphia: Lippincott-Raven Publishers.

15. Hayes RJ, Marsh K, Snow RW, 1992. Case-control studies of severe malaria. J Trop Med Hyg 95: 157-166.

16. D'Alessandro U, Olaleye B, Langerock P, Bennett S, Cham K, Cham B, Greenwood BM, 1997. The Gambian National Impregnated Bed Net Programme: evaluation of effectiveness by means of case-control studies. Trans R Soc Trop Med Hyg 91 : 638-642.

17. Curtis CF, Maxwell CA, Finch RJ, Njunwa KJ, 1998. A comparison of use of a pyrethroid either for house spraying or for bednet treatment against malaria vectors. Trop Med Int Health 3: 619-631.

18. Grandin BE, 1988. Wealth Ranking in Smallholder Communities: A Field Manual. Rugby: Intermediate Technology Development Group.

19. Rodrigues L, Kirkwood B, 1990. Case-control designs in the study of common diseases: updates on the demise of the rare disease assumption and the choice of sampling scheme for controls. Int J Epidemiol 19: 205-213.

20. Last JM, 1995. Dictionary of Epidemiology. Oxford: Oxford University Press.

21. Alexander N, 2004. Triangle plots of three-level explanatory variables. Significance 1: 130-131.

22. Bruzzi P, Green SB, Byar DP, Brinton LA, Schairer C, 1985. Estimating the population attributable risk for multiple risk factors using case-control data. Am J Epidemiol 122: 904-914.

23. Armitage P, Berry G, Matthews JNS, 2001. Statistical Methods in Medical Research. Oxford: Blackwell Scientific Publications.

24. Kroeger A, Mancheno M, Alarcon J, Pesse K, 1995. Insecticideimpregnated bed nets for malaria control: varying experiences 
from Ecuador, Colombia, and Peru concerning acceptability and effectiveness. Am J Trop Med Hyg 53: 313-323.

25. Secretaría de Salud del Amazonas, 1999. Reunión Tripartita Brasil, Colombia, Perú. Leticia: Secretaría de Salud del Amazonas.

26. Magris Crestini M, 2004. Malaria Control Trial Using Lambdacyhalothrin Treated Nets in Yanomami Communities in Amazonas State, Venezuela. Department of Infectious and Tropical Diseases: London School of Hygiene and Tropical Medicine (University of London).

27. Tadei WP, Dutary Thatcher B, 2000. Malaria vectors in the Brazilian Amazon: Anopheles of the subgenus Nyssorhynchus. Revista do Instituto de Medicina Tropical de Sao Paulo 42: 87-94.

28. Osorio L, Todd J, Bradley DJ, 2004. Travel histories as risk factors in the analysis of urban malaria in Colombia. Am J Trop Med Hyg 71: 380-386.

29. van der Hoek W, Konradsen F, Dijkstra DS, Amerasinghe PH, Amerasinghe FP, 1998. Risk factors for malaria: a microepidemiological study in a village in Sri Lanka. Trans $R$ Soc Trop Med Hyg 92: 265-269.

30. Castilla RE, Sawyer DO, 1993. Malaria rates and fate: a socio- economic study of malaria in Brazil. Social Sci and Med 37: $1137-1145$.

31. Guthmann JP, Hall AJ, Jaffar S, Palacios A, Lines J, LlanosCuentas A, 2001. Environmental risk factors for clinical malaria: a case-control study in the Grau region of Peru. Trans $R$ Soc Trop Med Hyg 95: 577-583.

32. Thompson R, Begtrup K, Cuamba N, Dgedge M, Mendis C, Gamage-Mendis A, Enosse SM, Barreto J, Sinden RE, Hogh B, 1997. The Matola malaria project: a temporal and spatial study of malaria transmission and disease in a suburban area of Maputo, Mozambique. Am J Trop Med Hyg 57: 550-559.

33. Gómez A, Sotomayor H, Lesmes A, 2000. Amazonía Colombiana: Enfermedades y Epidemias. Un Estudio de Bioantropologia Histórica. Bogotá: Panamericana Formas e Impresos S.A.

34. Alves FP, Durlacher RR, Menezes MJ, Krieger H, Silva LH, Camargo EP, 2002. High prevalence of asymptomatic Plasmodium vivax and Plasmodium falciparum infections in native Amazonian populations. Am J Trop Med Hyg 66: 641-648.

35. Salzano FM, Callegari-Jacques SM, 1988. South American Indians: A Case Study in Evolution. Oxford: Clarendon Press. 